\title{
Performance Appraisal of Enterprise Middle-Level Management Based on Fuzzy Comprehensive Evaluation
}

\author{
Liu Bo ${ }^{1, a}$, Zhang $\mathrm{Li}^{\mathrm{i}, \mathrm{b}}$ \\ ${ }^{1}$ Business School, Hohai University.Nanjing, China \\ ${ }^{2}$ Business School, Jinling Institute of Technology.Nanjing, China \\ a jsliubo@yahoo.cn, ${ }^{b}$ nj.teacher@163.com
}

Keywords:fuzzy comprehensive evaluation; performance appraisal

\begin{abstract}
Based on the study of ent erprise middle-level management performance appraisal index, this paper sets up the fuzzy comprehensive evaluation model of $m$ iddle-level management performance and carries out the e mpirical study, wh ich offers theor etic and realistic basis for strengthening middle-level management performance appraisal.

At present, the ef fective performance appraisal on enterprise middle-level managements is playing an increasing important role in human resource ma nagement and determines the basis of promoti on and reward for enterprise $m$ iddle-level managements. Therefore, building a scie ntific detection, inspection and evaluation syste $\mathrm{m}$, which is used for enterprise $\mathrm{m}$ angers, is a key for ef fectively managing enterprise middle-level managements.
\end{abstract}

\section{The Principles For The Performance Appraisal Of Enterprise Middle-Level Managements}

In order to achieve the expected perfor mance appraisal management skills, we should abide by the following basic principles in the performance appraisal:

A. The Principle of Openness

The standards, procedures and responsibilities of enterprise performance appraisal should be open to the staff.

B. The Principle of Objectivity

According to the standards of per formance appraisal, performance appraisal should objectively carry out examinations[1].

C. The Principle of feedback

The result of per formance appraisal should be sent back to the evaluated person to play the education and development function of performance appraisal.

D. The Principle of work-focus evaluation

Performance appraisal index refers to the output from which to assess the work, and it is to solve what question is evaluated[2].

\section{The Performance Appraisal Index System Design of Enterprise Middle-Level Management}

The performance appraisal index syste $m$ of e nterprise middle-level management includes: (1) one' own quality, including physic al quality and ideological quality; (2) work attitude, including responsibility awareness and ente rprising spirit; (3) actual achievement of work, including achievement of goal and team construction; (4) work ability, including prof ession competence, leadership, innovation ability and the ability of handling the emergency. the index set is divided into two levels by us: the first-level and the second-level index set are : $U=\left\{U_{1}, U_{2}, U_{3}, U_{4}\right\}$, $U_{1}=\left\{V_{11}, V_{12}\right\}, U_{2}=\left\{V_{21}, V_{22}\right\}, U_{3}=\left\{V_{31}, V_{32}\right\}, U_{4}=\left\{V_{41}, V_{42}, V_{43}, V_{44}\right\}$. 


\section{The fuzzy comprehensive evaluation in performance appraisal of enterprise middle-level management}

E. Construction of fuzzy comprehensive evaluation in the performance appraisal of enterprise middle-level management

(1) Determination of the facts in comprehensive evaluation

Total numbers of the $f$ irst-level evaluation index and the second-level evaluation index are four and ten respectively. The score of every level is as follows: $v_{i}(i=1, \cdots, 5), v_{1}=100$ (Excellent), $v_{2}=80$

(Good), $v_{3}=70$ (Moderate), $v_{4}=60$ (Bad), $v_{5}=40$ (Worse), so, $V=\left(v_{1}, v_{2}, v_{3}, v_{4}, v_{5}\right)_{[3]}$.

(2) Determination of index weight

1. Construction of important judgment matrix

We adopt the AHP method to determine the index weight of main factor and sub-factor levels[4].

The estimated value of the relative im portance of index $\mathrm{i}$ to index $\mathrm{j}$ is denoted by $a_{i j}$, thus, the comments of all the experts make up a group of fuzzy judgment matrixes as follows:

$$
A=\left[\begin{array}{lll}
a_{11} & a_{12} & a_{13} \\
a_{21} & a_{22} & a_{23} \\
a_{31} & a_{32} & a_{33}
\end{array}\right], \quad a_{i i}=1, a_{i j}=1 / a_{j i} \text {, plus } a_{i j}>0 .
$$

Construction of judgment matrix mainly relies on 1-9 scaling.

Take the every factor weight of wo rk ability in Table II as the example, according to experts' consultation scores, we can construct the important judgment matrix:

$A=\left(\begin{array}{cccc}1 & 3 & 5 & 7 \\ \frac{1}{3} & 1 & 3 & 4 \\ \frac{1}{5} & \frac{1}{3} & 1 & 3 \\ \frac{1}{7} & \frac{1}{4} & \frac{1}{3} & 1\end{array}\right)$

2.Calculate the weight value of every factor

We can use the method of $W_{i}=\frac{1}{n} \sum_{j=1}^{n} \frac{a_{i j}}{\sum_{k=1}^{n} a_{k j}} \quad(i=1,2, \ldots n)$ and get as follows: $w_{1}=0.0631, \quad w_{2}=0.1101, \quad w_{3}=0.6171, \quad w_{4}=0.2097$

3.Consistency Check

According to the formula $\lambda_{\max }=\frac{1}{n} \sum_{i=1}^{n} \frac{(A W)_{i}}{W_{i}}$, we can obtain the most obvious feature of matrix $\mathrm{A}: \lambda_{\max }=4.2298$, then we put the numerical value into the formula $C I=\frac{\lambda_{\max }-n}{n-1}=0.0766$, and $\mathrm{RI}$ indices the average coefficient of random one-time.

According to the form ula, $C R=\frac{C I}{R I}=\frac{0.0766}{0.9}=0.0851<0.1$, judgment matrix has satisfactory consistency. In the light of above methods, we can calculate in Table 1:

TABLE 1 DISTRIBUTION OF EACH FACTOR'S WEIGHT VALUE

\begin{tabular}{|l|l|l|l|l|l|l|l|l|l|}
\hline$U_{1}$ & \multicolumn{2}{|l|}{$U_{2}$} & \multicolumn{2}{l|}{$U_{3}$} & \multicolumn{4}{l|}{$U_{4}$} \\
\hline 0.0631 & \multicolumn{3}{|l|}{0.1101} & 0.6171 & 0.2097 & \\
\hline$V_{11}$ & $V_{12}$ & $V_{21}$ & $V_{22}$ & $V_{31}$ & $V_{32}$ & $V_{41}$ & $V_{42}$ & $V_{43}$ & $V_{44}$ \\
\hline 0.0105 & 0.0525 & 0.0551 & 0.0551 & 0.4628 & 0.1543 & 0.112 & 0.0499 & 0.0311 & 0.0167 \\
\hline
\end{tabular}

(3) Fuzzy comprehensive appraisal

Concrete evaluation adopts the fuzzy calculation $\mathrm{m}$ ethod: if $\mathrm{A}$ and $\mathrm{B}$ are the fuzzy matrices of dimensions $\mathrm{n} \times \mathrm{m}$ and $\mathrm{m} \times \mathrm{l}$, thus the their product is that $\mathrm{C}=\mathrm{A} \cdot \mathrm{B}[5]$, which is the $\mathrm{m}$ atrix of dimension $\mathrm{n} \times 1$, and its entries are: 


$$
C_{i j}=\underset{k=1}{\stackrel{m}{\vee}}\left(a_{i k} \wedge b_{k j}\right)(i=1,2, \cdots, n ; j=1,2, \cdots, I)
$$

The mark" $\vee$ "means $a \vee b=\max (a, b)$, and the $m$ ark " $\wedge$ "means: $a \wedge b=\min (a, b)$. Find $t$ he comprehensive evaluation matrix $B_{i}$ for each $U_{i} \quad(\mathrm{i}=1,2,3,4), B_{i}=W_{i} \bullet R_{i} \quad$ [3], the evaluation matrix (membership matrix) on $U$ is: $B=\left(B_{1}, B_{2}, B_{3}, B_{4}\right)^{\mathrm{T}}$, and the weight vector is $W_{1 \times 5}$. The comprehensive evaluation matrix of $\mathrm{U}$ is $\mathrm{A}=\mathrm{W} \cdot \mathrm{B}$.

\section{F. Analysis of examples}

According to the designed index sys tem, we invite ten experts to $m$ ake scores on perfor mance appraisal factors of Mr. /Mrs. Li by using the software Matlab.

\begin{tabular}{|c|c|c|c|c|c|c|c|c|c|c|}
\hline & $V_{11}$ & $V_{12}$ & $V_{21}$ & $V_{22}$ & $V_{31}$ & $V_{32}$ & $V_{41}$ & $V_{42}$ & $V_{43}$ & $V_{44}$ \\
\hline $\mathrm{W}$ & 0 & \multicolumn{3}{|c|}{$\begin{array}{lllllllllllllllll}0 & 0 & 0 & 0 & 0 & 0 & 0 & 0\end{array}$} & & & & & & \\
\hline $\mathrm{B}$ & 0 & 0 & 0.1 & 0.06 & 0.08 & 0.03 & 0 & 0.02 & 0.13 & 0.07 \\
\hline$M$ & 0.16 & 0.1 & 0.15 & 0.21 & 0.26 & 0.21 & 0.3 & 0.23 & 0.14 & 0.16 \\
\hline $\mathrm{G}$ & 0.42 & 0.36 & 0.41 & 0.36 & 0.38 & 0.4 & 0.42 & 0.41 & 0.31 & 0.36 \\
\hline $\mathrm{E}$ & 0.42 & 0.54 & 0.34 & 0.37 & 0.28 & 0.36 & 0.28 & 0.34 & 0.42 & 0.41 \\
\hline
\end{tabular}

When we use the model of fuzzy com prehensive evaluation of enterprise $m$ iddle-level management, we can calculate the ef fect of wo rk ability on the perfor mance evaluation is as follows:

$$
B_{4}=W_{4} \bullet R_{4}=\left(\begin{array}{lll}
0.1120 .04990 .03110 .0167
\end{array}\right) \bullet\left[\begin{array}{ccccc}
0 & 0 & 0.3 & 0.42 & 0.28 \\
0 & 0.02 & 0.23 & 0.41 & 0.34 \\
0 & 0.13 & 0.14 & 0.31 & 0.42 \\
0 & 0.07 & 0.16 & 0.36 & 0.41
\end{array}\right]
$$

$=(0,0.0311,0.112,0.112,0.112)$

In a similar way, the comprehensive evaluation results can be obtained:

$$
\begin{aligned}
& B_{1}=(0,0,0.0525,0.0525,0.0525), B_{2}=(0,0.0551,0.0551,0.0551,0.0551), \\
& B_{3}=(0,0.08,0.26,0.38,0.28)
\end{aligned}
$$

Therefore, the second -level comprehensive evaluation result of $\mathrm{Mr} . / \mathrm{Mrs} \mathrm{Li}$ is as follows:

$$
\mathrm{A}=\mathrm{W} \cdot \mathrm{B}=(0.0631,0.1101,0.6171,0.2097) \cdot\left[\begin{array}{ccccc}
0 & 0 & 0.0525 & 0.0525 & 0.0525 \\
0 & 0.0551 & 0.0551 & 0.0551 & 0.0551 \\
0 & 0.08 & 0.26 & 0.38 & 0.28 \\
0 & 0.0311 & 0.112 & 0.112 & 0.112
\end{array}\right]
$$

$=(0,0.08,0.26,0.38,0.28)$

Therefore, Mr. /Mrs. Li got the sc ores of perform ance evaluation: $100 * 0.28+80 * 0.38+70 * 0.26+60 * 0.08+40 * 0=81.4$, which can be ranked as good. From the prim ary evaluation result, we can see the actual work achievement of Mr. / Mrs. Li is evaluated as good.

\section{References}

[1]Geng Liping and Wang Zhijun, The Applicati on Study of Fuzzy Com prehensive Evaluation Method in The Enterprise Staffs Perform ance Appraisal [J]. Chinese Management Informatization, 2007(2).

[2]Xia Pingjian,Fuzzy Comprehensive Evaluation of Enterprise Management . Study on Question[J], $2010(63)$.

[3]Huang Liangwen an $d$ ZhengWuyi,The Principles of Statistics. Beijing: Chinese Sta tistic Press[M], 2010(6).

[4]Zhang Qi,The Study on Constructing perform ance Evaluation System of the enterprise middle-level management [D]. Liaoning Technical University, 2006.

[5]Fang Qiulian, Liu Zaiming,Performance Evaluation of Enterprise Managers Based on the Fuzzy Comprehensive Evaluation [J]. Practice and Cognition of Mathematics 2006 (7). 